\title{
A CONCEPTUAL MODEL TO MEASURE ERP USER-VALUE
}

\author{
Mohamed A. Lotfy, Regis University, mlotfy@regis.edu \\ Leila Halawi, Embry Riddle Aeronautical University, halawil@erau.edu
}

\begin{abstract}
The critical factors in the onward and upward phase that maximize the value o the enterprise resource planning $(E R P)$ system from the user's point of view remain unidentified. A recent study of a public sector organization in the state of Colorado showed that the users' perspectives regarding the benefits of an ERP system are unrecognized, as well as how the users of the ERP system view the ERP benefits post-implementation. The purpose of this study is to determine the factors that maximize the value of the implemented ERP system in the onward and upward phase postimplementation from the user's point of view (ERP user value), and how these factors affect the ERP user productivity, effectiveness, and internal efficiency which are major issues for management. A proposed conceptual structural model, based on the Technology-Organization-Environment (TOE) framework, is presented. It is posited that the conceptual model can be used to predict the post-implementation factors from the ERP user's point of view and measure their impact on the overall ERP benefits for the organization. The research question, hypotheses, and current state of research are presented and discussed.
\end{abstract}

Keywords: Enterprise Resource Planning (IT), ERP User-Value, Technology-Organization-Environment (TOE), PLS-SEM

\section{INTRODUCTION}

Enterprise resource planning (ERP), the most complex and largest enterprise system, is the core business process management software for organizations, which provides cost savings, improved planning and operations, and organizational growth. Currently, many small, medium, and large organizations utilize some form of an ERP system in their operations [62]. According to Koch [32], ERP systems provide a holistic view of the business with the ERP technology infrastructure as the core that supports the strategy, organization, people, and business environment. Stephenson and Sage's [59] ERP architectural model identified the technology, processes, and the people as the core components of the ERP environment. People (ERP users) are an integral part of the ERP environment and can influence the success or failure of the ERP system $[14,32]$.

ERP implementation is a strategically approached complex process of technology innovation as well as organizational and process change management that affects the entire organization [2]. The ERP implementation purpose is to permit the organization to assimilate the information systems throughout the organization thus allowing the organization to use the ERP system capabilities to seek a long-term sustainable competitive advantage $[26,51]$. Achieving a competitive advantage requires successful planning and implementation of the ERP system, refinement of the business process, and that the organization's strategic direction is in line with the ERP system performance post-implementation [24].

According to Velcu [65], the ERP system lifecycle consisted of three phases, the project, shakedown, and onward and upward phases. Law, Chen, and $\mathrm{Wu}$ [34] defined the ERP project lifecycle as consisting of four phases, adaptation, acceptance, routinization, and infusion. From the different definitions of the ERP lifecycle, the ERP post-implementation phase consists of the shakedown phase (routinization) and the onward and upward phase (infusion). In the shakedown or routinization phase, after the ERP system goes live, the ERP system's performance is tuned and integrated for normal use. In the onward and upward phase, infusion phase, the organization uses the ERP system for the day-to-day organizational operations as well as using it effectively to its maximum potential [34, 65]. Despite implementing and having a functional ERP system, the organization needs to measure the impact of the ERP technology on the organization post implementation. Esteves' [16] study showed, "the dimensions of ERP benefits are interconnected and the realization of ERP benefits is a continuum cycle along the ERP postimplementation axis" (p. 25). 
McCubbrey and Fukami's [43] study pointed out the there is a relationship between how users react to the ERP system and ERP success. Understanding employee reactions to the ERP system should help in assessing why some ERP implementations are more successful than other implementations [14]. User's perceived benefits of usefulness and usability of the ERP system affect the behavioral intention to use the ERP system [6]. Wu [65] posited that users' perceived benefits impact ERP implementation success, thus, identifying these benefits from the user's perspective is important, critical, and imperative.

The question of the ERP system's value to the organization and end users is and has been a key issue [53]. Uwizeyemungu and Raymond [64] defined ERP business value as "the value added by automational, informational and transformational effects of ERP capabilities upon the firm's operational and managerial processes" (p. 69). The ERP value to the user should not only depend on the ERP system functionality, but also on the tangible and intangible benefits of the user's experience using the system [24, 23]. Moon's [44] meta-analysis of ERP research identified the following questions, "Is an ERP system of any value to an organization? What values an ERP system brings to an organization? How do we measure the value of an ERP system?" (p. 244). Addo-Tenkorang and Helo's [1] research showed that some ERP studies raised the same questions raised by Moon [44] regarding ERP value. McCubbrey and Fukami's [43] study of a public sector organization in the state of Colorado indicated that there are mixed points of view regarding the value of the installed ERP system between management and end-users.

There is a need for a study to investigate how the technological, organizational, and environmental factors, which provide ERP user value, affected the ERP user productivity, effectiveness, and internal efficiency, which are major issues for management regarding implementing and maintaining ERP systems. The purpose of this research is to investigate the relationships between the factors that positively affect the productivity, effectiveness, internal efficiency, and coordination, thus, leading to maximize the value of the ERP system from the ERP user's point of view and how they correlate to ERP value post-implementation. The paper begins by reviewing the relevant literature in the area of ERP post-implementation and ERP success. We then present our conceptual model to measure ERP user-value. The final section provides the research questions, hypotheses, and current state of the research.

\section{REVIEW OF LITERATURE}

This section presents a review of the related research work, models, and frameworks supporting this study. The main objective of this literature review effort was to attain clear understanding of the state of ERP post-implementation success research, the use of the TOE framework in ERP studies, as well as identifying the different dimensions and factors utilized to measure ERP success.

Most of the post-implementation studies the literature review identified investigated the factors impacting ERP success, ERP efficiency, ERP effectiveness and benefits, organizational performance and structure, organizational culture, benefits and knowledge, ERP assimilation, ERP usage, risk factors, job and computing satisfaction. The remaining parts of this section provide a summary of these studies.

\section{Factors Impacting ERP Success}

Ifinedo, Rapp, Ifinedo, and Sundberg [25] tested the relationships between the constructs of the extended ERP systems success measurement model in an organizational context post implementation. Ifinedo et al. [25] showed that the constructs of system quality, service quality, individual impact, workgroup impact, and organizational impact are strongly relevant in measuring ERP success post implementation. Law et al. [34] showed that maintenance and support activities in the post-implementation phase are critical factors for ERP success, and organizations should plan for them in the ERP implementation phase. Zhu, Li, Wang, and Chen [68] developed an integrative model using the Technology-Organization-Environment (TOE) framework to explain ERP postimplementation success from the technological (implementation quality), organizational, and environmental (external support) aspects. Zhu et al. [68] results indicated that ERP implementation quality (project management and system configuration) and organizational readiness (leadership involvement and organizational fit) significantly influenced post-implementation success.

\section{ERP Efficiency, Effectiveness, and Benefits}


Karimi, Somers, and Bhattacherjee [30,31] indicated that ERP systems provide better process efficiency leading to more effectiveness and flexibility, which could improve profitability, earnings valuation, and competitiveness. Häkkinen and Hilmola [22] examined the differences between user evaluations of ERP system success in the shakedown and the onward and upward phases post-implementation. Federici [17] assessed ERP outcomes (economic results, management control, and operating efficiency) as measures of ERP success in the shakedown phase post-implementation. Madapusi and D'Souza [40] showed that the ERP system in the onward and upward phase allowed the organization to achieve overall operational performance enhancement including information quality, inventory management, and on-time delivery enhancements. Rich and Dibbern [54] found that crossfunctional collaboration influence ERP benefits post-implementation. Kanellou and Spathis [29] indicated that the ERP system provided operational accounting benefits in terms of cost and time reduction in addition to increased flexibility.

\section{Organizational Performance and Structure}

Bendoly and Cotteleer [5] suggested that if a task-technology misfit existed, managers and users might circumvent the ERP system rule-structures. Chou and Chang [11] indicated that the customization and organizational mechanisms significantly affected intermediate ERP post-implementation benefits, which affected the overall ERP benefits. Yoon [67] showed that employees' organizational citizenship behaviors significantly influenced ERP success and operational success. Chen and Wang [10] developed a model to measure the effect of ERP system on the firm's performance post-implementation. Velcu [65] tested the interrelations between strategic alignment, management of the ERP implementation, process changes, and the business performance of organizations that implemented ERP systems. Velcu [65] found that in the post-implementation phase, the use of the ERP system improved organizational efficiency, which affected the financial performance. Gallagher and Gallagher [19, 20] studied the organizational support structures post-implementation. They found that the post-implementation support structures are either a centralized cross-functional team structure or a distributed hybrid structure.

Kallunki, Laitinen, and Silvola [28] demonstrated that the ERP systems and formal management control systems jointly improved the firm performance. Cao, Nicolaou, and Bhattacharya [7] examined in a longitudinal study the influence of observed performance benefits, active management interventions, and timing considerations as performance enhancing measures post-implementation. Ha and Ahn [21] studied the impact of organizational support (top management support, competency of the internal ERP team, user training, and inter-department collaboration and communication) and continuous improvement efforts (continuous process improvement and continuous systems integration/extension) on ERP performance post-implementation. Ha and Ahn [21] indicated that continuous improvement efforts, and on-going organizational support positively influence ERP performance post-implementation. They further stated that "top management support was found to have continuous significant importance in the post-implementation stage influencing user training, communication, and collaboration between departments" [21, p.11]. Ram, Corkindale, and $\mathrm{Wu}$ [52] reported that training, education, and system integration significantly influenced ERP system performance post-implementation. Galy and Sauceda [18] showed that ERP post-implementation practices, increased technological competence, relationships with outside experts, top management support, and information sharing between departments, positively impacted the financial performance, but long-range planning negatively affected the earnings.

\section{Organizational Culture, Benefits, and Knowledge}

Seddon, Calvert, and Yang [56] developed a model to measure organizational benefits of enterprise systems using the following factors, functional fit, overcoming organizational inertia, integration, process optimization, improved access to information, and on-going major enterprise systems business improvement projects. Seddon et al. [56] results indicated that the identified model factors are important for organizational benefits post-implementation. They found that the functional fit and overcoming organizational inertia are the key factors for achieving organizational benefits in the shakedown phase and integration. In addition, process optimization, improved access to information, and on-going major enterprise systems business improvement projects drive the organizational benefits in the onward and upward phase [56].

Shao, Feng, and Liu [57] examined how organizational culture (development, hierarchical, group, and rational culture) and knowledge sharing (explicit and implicit) mediated the effect of transformational leadership on ERP 
success in the assimilation phase post-implementation. Shao et al. [57] found "that group culture and rational culture have direct impact on tacit knowledge sharing, while hierarchical culture indirectly impacts explicit knowledge sharing" (p. 2410). They further stated that top management needs "to pay attention to ERP knowledge sharing even after the implementation has completed and the system has been devoted into daily use" (p. 2410).

\section{ERP Assimilation}

Liang, Saraf, Hu, and Xue [36] study demonstrated that strong top management beliefs, role, and participation in the post-implementation assimilation efforts led to a higher extent of ERP assimilation in the organization. Jones, Zmud, and Clark Jr [27] examined the difficulties associated with ERP assimilation (installed ERP system functionality and the extent of system usage) in the onward and upward phase post implementation. Jones et al. [27] provided a postadoptive ERP system structure model identifying the relationships between software training interventions, work process training interventions, experiential interventions, software understanding, work process understanding, and installed ERP functionality and their impact on system usage and benefits.

\section{ERP Usage}

Clark, Jones, and Zmud [13] provided a dynamic information feedback post-adoptive ERP system structure model. The model identified the relationships between primary interventions (software training, work process training, and experiential, transitional outcomes (software systems understanding and work process understanding), intermediate outcomes (extent of features implementation and system usage), and system outcome (system benefits) to help organizations facilitate the ERP usage to enhance the business value. Saeed, Abdinnour, Lengnick-Hall, and Lengnick-Hall's [55] found that at the post-adoption stage user acceptance mediated the relationship between actual use and shared understanding. They also found "user acceptance at both pre- and post-adoption stages are critical factors when usage is mandatory" (p. 659-660). Lin [37] showed that while ERP information quality and ERP system quality impacted ERP system usage through user satisfaction and perceived usefulness, top management support directly impacted ERP system usage and indirectly through perceived usefulness. Chang, Chou, Yin, and Cecilia [9] proposed a framework to measure the impact of ERP usage on individual performance (individual productivity, customer satisfaction, and management control). Chang et al. [9] investigated the mediating effects of decision support, work integration, and customer service on the impact of post-implementation learning on ERP usage.

\section{Risk Factors}

Peng and Nunes' [49] study identified that the organizational (processes and procedures) risks cause ERP system failure in the post-implementation phase. Tsai, Lee, Shen, and Yang [63] found that lack of top management participation, the firm's policies and process, and the lack of organizational transformation are the top organizational environment risks that affect ERP performance post- implementation. Singh, Singh, and Pereira [58] showed that users' resistance to technology change and applied change management techniques hinder ERP success. Peng and Nunes [48] found that many ERP barriers and risks are interrelated and originated from the organizational barriers and risks. Pan, Nunes, and Peng [47] found that the organizational change and human-related risks led to ERP failure post-implementation. Mathrani and Mathrani [42] showed that there is a link between ERP data transformation processes and risk-mitigating benefits. López and Salmeron [38, 39] provided a model to identify and manage ERP maintenance project risks.

\section{Job and Computing Satisfaction}

Larsen [33] investigated end-user computing satisfaction during the shakedown phase post-implementation in ten subunits of an international manufacturing organization. Larsen [33] found that "communication and decisionmaking patterns between users and experts locally, and communication with peers in organizational units other than the respondent's own - contributed more consistently to individual end-user computing satisfaction" (p. 666). Larsen's [33] study showed that "user training plays a role in explaining the users' perceptions of the relevance of the ERP project's business objectives for the organization and for their own jobs" (p. 666). Morris and Venkatesh [45] developed a model to measure the impact of the ERP system on the relationship between employees' job characteristics (task significance, task identity, skill variety, autonomy, and feedback) and their job satisfaction post 
implementation. The results indicated that "the ERP system implementation moderated the effects of skill variety, autonomy, and feedback on job satisfaction" and "task identity and task significance had direct positive effects on job satisfaction" [45, p. 152].

\section{ERP End User}

According to Peslak and Boyle [50], "people are one of important variables in a winning ERP strategy" (p. 12) Singh et al. [58] argued that the ERP post-implementation research field still lacks insights regarding human factors. Althonayan and Papazafeiropoulou [3] asserted, "Individual performance is an essential indicator of organizational performance"; thus, "studying the impact of ERP systems on stakeholders' performance is a significant way to assess the utility of this software and how it contributes to performance efficiency and effectiveness" (p. 4076). Dezdar and Ainin [15] found that the satisfaction of the ERP users with the implemented ERP system reliability, functionality, flexibility, and user friendliness features is necessary for the success of an ERP implementation. Morris and Venkatesh [45] showed that the ERP system implementation moderated the relationships between job characteristics (skill variety, autonomy, and feedback) and the end user's job satisfaction. Maldonado and Sierra [41] indicated that user satisfaction significantly influences ERP business improvement success.

Users' perceived benefits of the usefulness and usability of the ERP system affected the behavioral intention to use the ERP system [5, 9, 35]. Chang et al. [8] asserted that the social context and social factors influence technology use. Chang et al. [8] study found that social factors, as an organizational characteristic, had the strongest effect on the ERP system usage. Chou, Lin, Lu, et al. [12] argued that effective ERP system use post-implementation was through knowledge gained from other users. Chou et al. [12] revealed that user self-efficacy enabled employees to share knowledge. Sykes, Venkatesh, and Johnson [60] showed that employee advice networks affect ERP postimplementation job performance.

\section{RESEARCH METHODOLOGY}

\section{Research Questions}

Our research centered upon the following research question:

1. From an ERP user's point of view, what are the factors that maximize the value of an ERP system for the user in the onward and upward phase?

2. Which post-implementation factors in the onward and upward phase maximize the value of an ERP system from the user's point of view and how significant are those factors?

Tornatzky and Fleischer's [61] technology, organization, and environment (TOE) framework is a conceptualization of the theory of diffusion of innovation regarding diffusion of technological innovation. The TOE framework provides a generic theory of technology diffusion to model and study information systems technology diffusion. The TOE framework addressed the three dimensions of diffusion of innovation, the technology, the organizational characteristics, and the environment. The TOE framework provided an environment context to the technology and organizational contexts as measures of IT performance success [4]. Different factors affect each of the TOE contexts. The formal and informal linking structures, firm size, slack resources, the communication processes, and informal linkages between the employees are some of the organizational context factors. The environment context factors are variables that include the industry characteristics and market Structure, technology support infrastructure, and government regulations. The Internal and external characteristics of the information technology innovation are the factors of the technology context [4].

The TOE framework provides an analytical approach to study the relationship between the contexts of ERP implementation success and enables measuring ERP adoption from multiple perspectives, management, IT professionals, and ERP users [46]. The proposed conceptual model in this study incorporates the TOE framework to predict the ERP user-value and its impact on the overall ERP benefits for the organization. The proposed conceptual model can be used to investigate the impact of the ERP technology capabilities, organizational systems in place, and environmental contexts on the success of the ERP system in the onward and upward phase, and measure their causal effect on the ERP user value. 


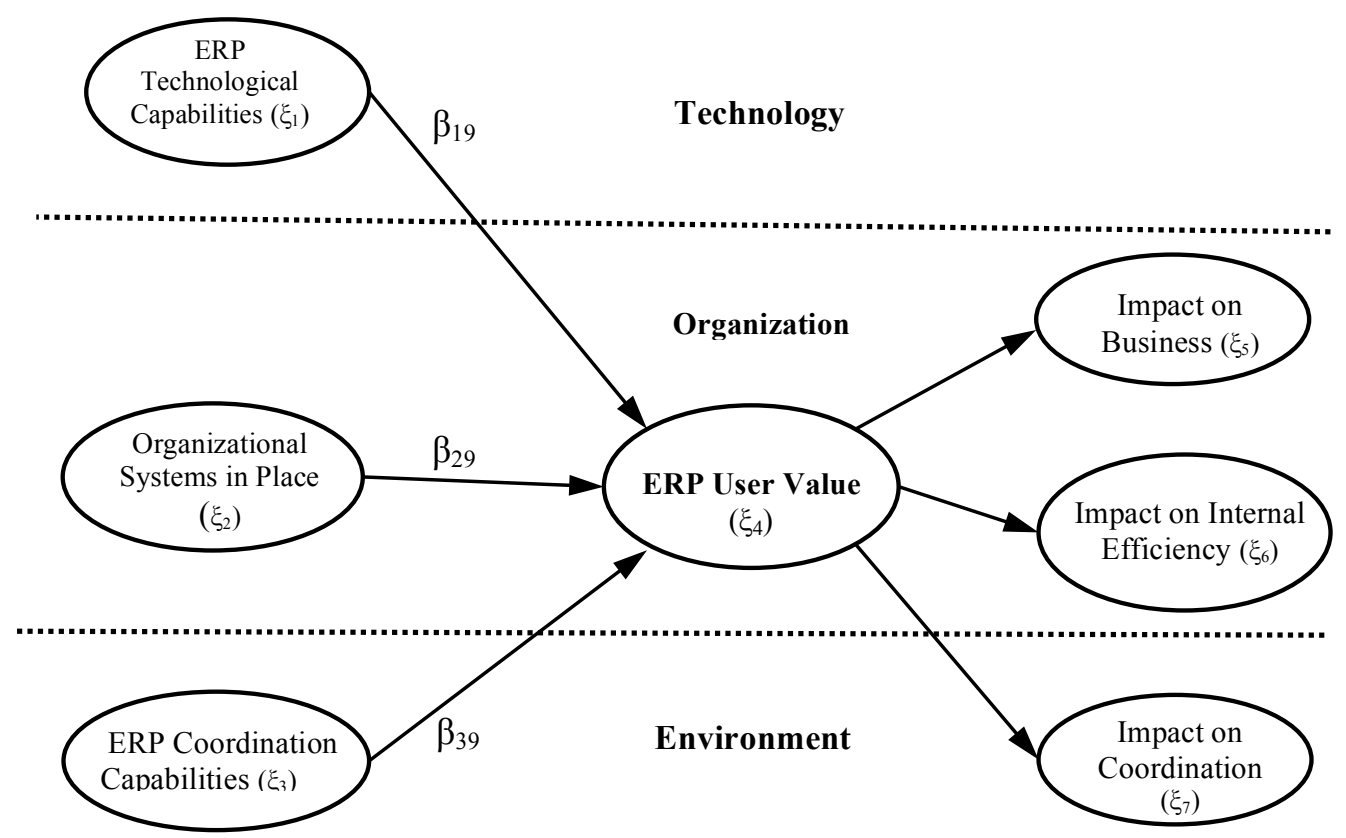

Figure 1. Conceptual Model

From the research structural model, see Figure 1 above, the following research hypotheses are proposed:

$\mathrm{H}_{1}$ : The ERP technological capabilities does not impact ERP user value $(\beta 19=0)$.

$\mathrm{H}_{2}$ : The organizational systems in place does not impact ERP user value $(\beta 29=0)$.

$\mathrm{H}_{3}$ : The ERP coordination capabilities does not impact ERP user value $(\beta 39=0)$.

We will utilize an online survey instrument to collect the required data. The target population for the study is organizational employees who use an implemented and operational ERP system for at least four years. A representative sample frame of the study target population will include multiple firms, higher education institutions, government entities, and local ERP and supply-chain management user groups in the Denver, CO metropolitan area.

The partial least squares structural equation modeling (PLS-SEM) approach utilizing Smart PLS will be used to explain the interactions and relationships between the different factors in the structural model (independent variables) and their causal effect on the ERP user value (dependent variable, a second order latent variable). The PLS-SEM approach will provide the needed explanatory analysis to test the structural model and testing the hypotheses statistically in a future publication.

\section{CONCLUSIONS}

There is a need for research that identifies the user's perspective regarding the benefits of an ERP system and how the users of the ERP system view the benefits of an ERP system. This paper introduces a conceptual structural model based on the TOE framework to predict the post-implementation factors from the ERP user point of view and their impact on the overall ERP benefits for the organization. This paper addresses an under-researched area the ERP post-implementation onward and upward phase, as well as how user acceptance of ERP value affect the firm's achieved ERP benefits. Investigating ERP users' points of views and perspectives regarding the impact of ERP user value provides information that could lead to a positive social change context in current ERP research.

This is a research in progress. To complete our analysis, the PLS-SEM analysis will utilize SmartPLS 3.2. Using a SEM approach allows for testing hypotheses about the relationships between observed (measured indicators) and 
latent variables (unobserved factors or constructs). In addition, SEM allows for estimating and correcting measurement errors. PLS-SEM permits assessing both the path model (inner model) and measurement model (outer model). The PLS-SEM analysis should pinpoint the post-implementation sustainability factors from the ERP user's point of view and their impact on the overall ERP benefits for the organization. The data analysis results as well as the PLS-SEM analysis of the structural model and testing the hypotheses statistically will be shared in a future publication.

The results of this study will help organizations adopting ERP systems maximize the value of the used ERP system. The outcomes of this study fills a gap in ERP research since it investigates the relationship between the ERP technology capabilities, organizational support systems and processes already in place, and ERP coordination capabilities, and how these factors impact ERP user-value. This study is important in that it goes beyond merely identifying how ERP systems can benefit an organization, by also providing a conceptual model to ascertain the real efficiencies from the ERP user's point of view that can sustain the ERP competitive advantage.

\section{REFERENCES}

1. Addo-Tenkorang, R., \& Helo, P. (2011). Enterprise resource planning (ERP): A review literature report. In Proceedings of the World Congress on Engineering and Computer Science (Vol. 2, pp. 1074-1080).

2. Aloini, D., Dulmin, R., \& Mininno, V. (2012). Risk assessment in ERP projects. Information Systems, 37(3), 183-199. doi:10.1016/j.is.2011.10.001

3. Althonayan, M., \& Papazafeiropoulou, A. (2013, January).Evaluating the performance on ERP systems in King Saud University (KSU): A stakeholders' perspective. In System Sciences (HICSS), 2013 46th Hawaii International Conference on (pp. 4074-4083). doi:10.1109/HICSS.2013.210

4. Baker, J. (2012). The technology-organization-environment framework. In Information Systems Theory (pp. 231-245). Springer New York. doi:10.1007/978-1-4419-6108-2_12

5. Bendoly, E., \& Cotteleer, M. J. (2008). Understanding behavioral sources of process variation following enterprise system deployment. Journal of Operations Management, 26(1), 23-44. doi:10.1016/j.jom.2007.03.002

6. Calisir, F., Gumussoy, C. A., \& Bayram, A. (2009). Predicting the behavioral intention to use enterprise resource planning systems: An exploratory extension of the technology acceptance model. Management Research News, 32(7), 597-613. doi:10.1108/01409170910965215

7. Cao, J., Nicolaou, A. I., \& Bhattacharya, S. (2013). A longitudinal examination of enterprise resource planning system post-implementation enhancements. Journal of Information Systems, 27(1), 13-39. doi:10.2308/isys50398

8. Chang M.K., Cheung, W., Cheng, C.H., \& Yeung, J. H.Y., (2008). Understanding ERP system adoption from the user's perspective. International Journal of Production Economics, 113(2), 928-942. doi:10.1016/j.ijpe.2007.08.011

9. Chang, H.-H., Chou, H.-W., Lin, C.-P.Y. and Cecilia, I. (2011). ERP post-implementation learning, ERP usage and individual performance impact. Paper presented at Pacific Asia Conference on Information Systems, Brisbane, Australia.

10. Chen, G., \& Wang, J. (2010, August). Analysis on performance evaluation system of ERP implementation. In Information Science and Management Engineering (ISME), 2010 International Conference of (Vol. 1, pp. 185188). IEEE. doi:10.1109/ISME.2010.135

11. Chou, S., \& Chang, Y. (2008). The implementation factors that influence the ERP (enterprise resource planning) benefits. Decision Support Systems, 46(1), 149-157. doi:10.1016/j.dss.2008.06.003

12. Chou, H. W., Lin, Y. H., Lu, H. S., Chang, H. H., \& Chou, S. B. (2014). Knowledge sharing and ERP system usage in post-implementation stage. Computers in Human Behavior, 33, 16-22. doi:10.1016/j.chb.2013.12.023

13. Clark, T. D., Jones, M. C., \& Zmud, R. W. (2009). Post adoptive ERP use behaviors: A dynamic conceptualization. Proceedings of the $27^{\text {th }}$ International Conference of the System Dynamics Society, Albuquerque, NM. Retrieved from http://www.systemdynamics.org/conferences/2009/proceed/papers/P1015.pdf

14. Dery, K., Grant, D., Harley, B., \& Wright, C. (2006). Work, organisation and enterprise resource planning systems: An alternative research agenda. New Technology, Work and Employment 21(3), 199-214. doi:10.1111/j.1468-005X.2006.00175.x 
15. Dezdar, S., \&Ainin, S. (2010). ERP implementation success in Iran: Examining the role of system environment factors. World Academy of Science, Engineering \& Technology, 66, 449-455.

16. Esteves, J. (2009). A benefits realisation road-map framework for ERP usage in small and medium-sized enterprises. Journal of Enterprise Information Management, 22(1/2), 25-35. doi:10.1108/17410390910922804

17. Federici, T. (2009). Factors influencing ERP outcomes in SMEs: A post-introduction assessment. Journal of Enterprise Information Management, 22(1/2), 81-98. doi:10.1108/17410390910922840

18. Galy, E., \& Sauceda, M. J. (2014). Post-implementation practices of ERP systems and their relationship to financial performance. Information \& Management, 51(3), 310-319. doi:10.1016/j.im.2014.02.002

19. Gallagher, K. P., \& Gallagher, V. C. (2012). Organizing for post-implementation ERP: A contingency theory perspective. Journal of Enterprise Information Management, 25(2), 170-185. doi: 10.1108/17410391211204400

20. Gallagher, K.P., \& Gallagher, V.C. (2010, January). An exploratory study of organizing structures for postimplementation ERP.2010 43rd Hawaii International Conference on System Sciences (HICSS) (pp. 1-10). doi:10.1109/HICSS.2010.56

21. Ha, Y. M., \& Ahn, H. J. (2013). Factors affecting the performance of Enterprise Resource Planning (ERP) systems in the post-implementation stage. Behaviour \& Information Technology, (ahead-of-print), 1-17. doi:10.1080/0144929X.2013.799229

22. Häkkinen, L., \& Hilmola, O. P. (2008). Life after ERP implementation: Long-term development of user perceptions of system success in an after-sales environment. Journal of Enterprise Information Management, 21(3), 285-310. doi:10.1108/17410390810866646

23. Hsu, P. F. (2013a). Commodity or competitive advantage? Analysis of the ERP value paradox. Electronic Commerce Research and Applications, 12(6), 412-424. doi:10.1016/j.elerap.2013.06.004

24. Hsu, P. F. (2013b). Integrating ERP and e-business: Resource complementarity in business value creation. Decision Support Systems, 56, 334-347. doi:10.1016/j.dss.2013.06.013

25. Ifinedo, P., Rapp, B., Ifinedo, A., \& Sundberg, K. (2010). Relationships among ERP post-implementation success constructs: An analysis at the organizational level. Computers in Human Behavior, 26(5), 1136-1148. doi:10.1016/j.chb.2010.03.020

26. Johansson, B. (2013). Feedback in the ERP value-chain: What influence has thoughts about competitive advantage. In Enterprise Information Systems of the Future (pp. 134-148). Springer Berlin Heidelberg. doi:10.1007/978-3-642-36611-6_10

27. Jones, M. C., Zmud, R. W., \& Clark Jr, T. D. (2008). ERP in practice: A snapshot of post-installation perception and behaviors. Communications of the Association for Information Systems, 23(1), 437-462.

28. Kallunki, J. P., Laitinen, E. K., \& Silvola, H. (2011). Impact of enterprise resource planning systems on management control systems and firm performance. International Journal of Accounting Information Systems, 12(1), 20-39. doi:10.1016/j.accinf.2010.02.001

29. Kanellou, A., \& Spathis, C. (2013). Accounting benefits and satisfaction in an ERP environment. International Journal of Accounting Information Systems, 14(3), 209-234. doi:10.1016/j.accinf.2012.12.002

30. Karimi, J., Somers, T. M., \& Bhattacherjee, A. (2007a). The role of information systems resources in ERP capability building and business process outcomes. Journal of Management Information Systems, 24(2), 221260. doi:10.2753/MIS0742-1222240209

31. Karimi, J., Somers, T. M., \& Bhattacherjee, A. (2007b). The impact of ERP implementation on business process outcomes: A factor-based study. Journal of Management Information Systems, 24(1), 101-134. doi:10.2753/MIS0742-1222240103

32. Koch, C. (2011, May). Closing the Blackbox? A Status on Enterprise Resource Planning (ERP) Studies in Information Systems Research. In Computer and Information Science (ICIS), 2011 IEEE/ACIS 10th International Conference on (pp. 409-414). IEEE. doi:10.1109/ICIS.2011.70

33. Larsen, T. J. (2009). A multilevel explanation of end-user computing satisfaction with an enterprise resource planning system within an international manufacturing organization. Computers in Industry, 60(9), 657-668. doi:10.1016/j.compind.2009.05.004

34. Law, C. C., Chen, C. C., \& Wu, B. J. (2010). Managing the full ERP life-cycle: Considerations of maintenance and support requirements and IT governance practice as integral elements of the formula for successful ERP adoption. Computers in Industry, 61(3), 297-308. doi:10.1016/j.compind.2009.10.004

35. Lee, D.H., Lee, S.M., Olson, D. L., \& Chung, S.H. (2010). The effect of organizational support on ERP implementation. Industrial Management \& Data Systems, 110(2), 269-283. doi:10.1108/02635571011020340

36. Liang, H., Saraf, N., Hu, Q., \& Xue, Y. (2007). Assimilation of enterprise systems: The effect of institutional pressures and the mediating role of top management. MIS Quarterly, 31(1), 59-87. 
37. Lin, H.F., (2010). An investigation into the effects of IS quality and top management support on ERP system usage. Total Quality Management \& Business Excellence, 21(3), 335-349. doi:10.1080/14783360903561761

38. López, C., \& Salmeron, J. L. (2014a). Dynamic risks modelling in ERP maintenance projects with FCM. Information Sciences, 256, 25-45. doi:10.1016/j.ins.2012.05.026

39. López, C., \& Salmeron, J. L. (2014b). Modeling maintenance projects risk effects on ERP performance. Computer Standards \& Interfaces, 36(3), 545-553. doi:10.1016/j.csi.2013.11.002

40. Madapusi, A., \& D'Souza, D. (2012). The influence of ERP system implementation on the operational performance of an organization. International Journal of Information Management, 32(1), 24-34. doi:10.1016/j.ijinfomgt.2011.06.004

41. Maldonado, M., \& Sierra, V. (2013). User satisfaction as the foundation of the success following an ERP adoption: An empirical study from Latin America. International Journal of Enterprise Information Systems (IJEIS), 9(3), 77-99. doi:10.4018/jeis.2013070104

42. Mathrani, S., \& Mathrani, A. (2013). Utilizing enterprise systems for managing enterprise risks. Computers in Industry, 64(4), 476-483. Doi:10.1016/j.compind.2013.02.002

43. McCubbrey, D. J., \& Fukami, C. V. (2009). ERP at the Colorado department of transportation: The whistle blower's dilemma. Communications of the Association for Information Systems, 24(1), 105-112.

44. Moon, Y. B. (2007). Enterprise resource planning (ERP): A review of the literature. International Journal of Management and Enterprise Development, 4(3), 235-264.

45. Morris, M., \& Venkatesh, V. (2010). Job characteristics and job satisfaction: Understanding the role of enterprise resource planning system implementation. Management Information Systems Quarterly, 34(1), 143161.

46. Oliveira, T., \&Martins, M. (2011). Literature review of information technology adoption models at firm level. Electronic Journal of Information Systems Evaluation, 14(1), 110-121.

47. Pan, K., Nunes, M. B., \& Peng, G. C. (2011). Risks affecting ERP post-implementation: Insights from a large Chinese manufacturing group. Journal of Manufacturing Technology Management, 22(1), 107-130. doi:10.1108/17410381111099833

48. Peng, G. C., \& Nunes, M. B. (2010, January). Interrelated barriers and risks affecting ERP post-implementation in China. In System Sciences (HICSS), 2010 43rd Hawaii International Conference on (pp. 1-10). IEEE. doi:10.1109/HICSS.2010.240

49. Peng, G. C., \& Nunes, M. B. (2009). Identification and assessment of risks associated with ERP postimplementation in China. Journal of Enterprise Information Management, 22(5), 587-614. doi:10.1108/17410390910993554

50. Peslak, A. R., \& Boyle, T. A. (2010). An exploratory study of the key skills for entry-level ERP employees. International Journal of Enterprise Information Systems (IJEIS), 6(2), 1-14. doi:10.3200/JOEB.82.5.267-275

51. Rahrovani, Y., \& Pinsonneault, A. (2012). On the business value of information technology: A theory of slack resources. In Information Systems Theory (pp. 165-198). Springer New York. doi: 10.1007/978-1-4419-61082.9

52. Ram, J., Corkindale, D., \& Wu, M. L. (2013). Implementation critical success factors (CSFs) for ERP: Do they contribute to implementation success and post-implementation performance?. International Journal of Production Economics, 144(1), 157-174. doi:10.1016/j.ijpe.2013.01.032

53. Ramdani, B. (2012). Information technology and organisational performance: Reviewing the business value of IT literature. In Information Systems Theory (pp. 283-301). Springer New York. doi:10.1007/978-1-4419-6108215

54. Rich, D., \& Dibbern, J. (2013). A team-oriented investigation of ERP post-implementation integration projects: how cross-functional collaboration influences ERP benefits. In Innovation and Future of Enterprise Information Systems (pp. 115-127). Springer Berlin Heidelberg.

55. Saeed, K. A., Abdinnour, S., Lengnick-Hall, M. L., \& Lengnick-Hall, C. A. (2010). Examining the impact of pre-implementation expectations on post-implementation use of enterprise systems: A longitudinal study. Decision Sciences, 41(4), 659-688. doi:10.1111/j.1540-5915.2010.00285.x

56. Seddon, P. B., Calvert, C., \& Yang, S. (2010). A multi-project model of key factors affecting organizational benefits from enterprise systems. MIS Quarterly, 34(2), 305-328.

57. Shao, Z., Feng, Y., \& Liu, L. (2012). The mediating effect of organizational culture and knowledge sharing on transformational leadership and Enterprise Resource Planning systems success: An empirical study in China. Computers in Human Behavior, 28(6), 2400-2413. doi:10.1016/j.chb.2012.07.011 
58. Singh, L. P., Singh, S., \& Pereira, N. M. (2010, July). Human risk factors in post-implementation phase of ERP in SMEs in India. In Technology Management for Global Economic Growth (PICMET), 2010 Proceedings of PICMET'10: (pp. 1-11). IEEE.

59. Stephenson, S. V., \& Sage, A. P. (2007). Architecting for enterprise resource planning. Information, Knowledge, Systems Management, 6(1), 81-121.

60. Sykes, T. A., Venkatesh, V., \& Johnson, J. L. (2014). Enterprise system implementation and employee job performance: Understanding the role of advice networks. MIS Quarterly, 38(1), 51-72.

61. Tornatzky, L.G., and Fleischer, M. (1990). The processes of technological innovation. Lexington, Massachusetts: Lexington Books.

62. Tsai, W. H., Chen, S. P., Hwang, E. T., \& Hsu, J. L. (2010). A study of the impact of business process on the ERP system effectiveness. International Journal of Business and Management, 5(9), 26-37.

63. Tsai, W. H., Lee, P. L., Shen, Y. S., \& Yang, C. C. (2009, December).The relationship between ERP software selection criteria and ERP success. In Industrial Engineering and Engineering Management, 2009. IEEM 2009. IEEE International Conference on (pp. 2222-2226). IEEE. doi:10.1109/IEEM.2009.5373085

64. Uwizeyemungu, S., \& Raymond, L. (2012). Impact of an ERP system's capabilities upon the realisation of its business value: A resource-based perspective. Information Technology and Management, 13(2), 69-90. doi:10.1007/s10799-012-0118-9

65. Velcu, O. (2010). Strategic alignment of ERP implementation stages: An empirical investigation. Information \& Management, 47(3), 158-166. doi:10.1016/j.im.2010.01.005

66. Wu, W. W. (2011). Segmenting and mining the ERP users' perceived benefits using the rough set approach. Expert Systems with Applications, 38(6), 6940-6948. doi:10.1016/j.eswa.2010.12.030

67. Yoon, C. (2009). The effects of organizational citizenship behaviors on ERP system success. Computers in Human Behavior, 25(2), 421-428. doi:10.1016/j.chb.2008.10.004

68. Zhu, Y., Li, Y., Wang, W., \& Chen, J. (2010). What leads to post-implementation success of ERP? An empirical study of the Chinese retail industry. International Journal of Information Management, 30(3), 265276. doi:10.1016/j.ijinfomgt.2009.09.007 